\title{
FLORESTAN FERNANDES E A DEFESA DA EDUCAÇÃO PÚBLICA
}

\author{
RoBerto LEHER*
}

\begin{abstract}
RESUMO: O artigo examina os estudos teóricos de Florestan Fernandes e sua elaboração dedicada à causa da educação pública em dois períodos: o da Lei de Diretrizes e Bases de 1961 e o compreendido entre a Constituinte de 19871988 e a elaboração da Lei de Diretrizes e Bases, até o ano de 1995. Aborda questões de método para o estudo das concepções do sociólogo sobre a educação pública e destaca a centralidade do conceito de capitalismo dependente para compreender as mudanças em sua perspectiva sobre os entraves que impossibilitaram, no Brasil, reformas educacionais universalistas, características das revoluções burguesas clássicas.
\end{abstract}

Palavras-chave: Florestan Fernandes. Capitalismo dependente. Revolução Burguesa. Educação pública. Lei de Diretrizes e Bases.

\section{Florestan Fernandes and the Defense of pUblic EdUCATION}

ABSTRACT: The article examines the theoretical studies of Florestan Fernandes and his elaboration dedicated to the cause of public education in two periods: the first concerning the Law of Directives and Basis for Brazilian Education from 1961 and the second between the constituent of 1987-1988 and the preparation of the Law of Directives and Basis for Brazilian Education, till the year of 1995. It addresses questions of method to the sociologist's concepts study on public education and highlights the centrality of the concept of dependent capitalism to understand the changes, in his perspective, that represented an obstacle to the Brazilian universalistic educational reforms that characterize classical bourgeois revolutions.

Key words: Florestan Fernandes. Dependent capitalism. Bourgeois revolution. Public education. Law of Directives and Basis for Brazilian Education.

\section{Florestan Fernandes et la défense de l'Éducation Publique}

RÉSUMÉ: L'article analyse les liens entre les études théoriques de Florestan Fernandes et son travail de réflexion dédié à la cause de l'éducation publique pendant deux périodes: celle de la Loi de Directives et Bases de 1961 et celle comprise entre la constitutante de 1987/88 et l'élaboration de la Loi de Directives et Bases jusqu'en 1995. Il aborde les questions de méthode pour l'étude * Doutor em Educação e professor titular da Faculdade de Educação da Universidade Federal do Rio
de Janeiro (UFRJ). E-mail: leher.roberto@gmail.com 
des conceptions du sociologue sur l'éducation publique et met en évidence le caractère central du concept de capitalisme dépendant pour comprendre les changements intervenus dans sa manière d'appréhender les entraves qui ont rendu impossibles, au Brésil, les réformes universalistes liées à l'éducation, caractéristiques des révolutions bourgeoises classiques.

Mots-clés: Florestan Fernandes. Capitalisme dépendant. Révolution bourgeoise. Éducation publique. Loi d'orientation.

\section{Introdução}

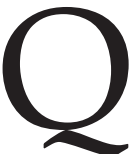

ual a atualidade de discutir Florestan Fernandes para melhor compreender o sentido atribuído pelo sociólogo à defesa da educação pública e, mais amplamente, os dilemas da escola pública de hoje? É possível identificar mudanças em sua perspectiva política sobre a problemática educacional? Em relação à primeira indagação, sua vasta produção bibliográfica, a relevância da cadeira de Sociologia da Universidade de São Paulo (USP) para a ciência social brasileira e sua atuação parlamentar poderiam fazer crer que esta indagação é inteiramente despropositada. Entretanto, a pergunta é pertinente, tendo em vista o brutal processo de "proscrição intelectual" (Candido, 1987, p. 35) a que Florestan foi submetido pela ditadura civil-militar. A última indagação, indissoluvelmente relacionada à anterior, exige um mergulho em seus escritos teóricos mais sistemáticos, conforme discussão adiante.

O seu afastamento compulsório da USP pelo Ato Institucional n. 5 (AI-5) foi um duro golpe em sua trajetória acadêmica, instituição em que o sociólogo fez, no sentido forte da palavra, uma carreira acadêmica, instaurou padrões determinados de trabalho acadêmico e construiu senão uma escola, intento que ele rejeitava, um coletivo de professores, assistentes e interlocutores que, sob sua liderança, forjaram parte importante da história das ciências sociais no Brasil. Em suas palavras, "a cadeira de Sociologia I era uma instituição dentro de outra instituição" (Fernandes, 1977,p. 185). A contrarrevolução se impôs na universidade com o protagonismo de uma inteligência aliada, alcançando editoras e órgãos de fomento. É forçoso reconhecer que o ambiente de medo teve eficácia: entre 1969 e 1979, período em que elaborou sua obra prima - A Revolução Burguesa no Brasil (1975), doravante RBB -, levantamento de artigos sobre sua obra identifica apenas quatro produções (Mariosa, 2007).

Considerando tal retrospecto, sua presença no espaço acadêmico brasileiro atual é digna de registro. Estudo sobre o estado da arte da presença de Florestan nas teses brasileiras (2000-2010) identificou 62 teses relacionadas com a sua obra. Entre as áreas, destacam-se: Ciências Sociais e Sociologia (23), Educação (15), História (8) e Serviço Social (7). O levantamento evidenciou que 17 resumos continham "Florestan 
Fernandes", 9 apresentavam a categoria "capitalismo dependente" e 28 valeram-se de seus conceitos para abordar a problemática do desenvolvimento (Freitas, et al., 2011). A produção bibliográfica que versa sobre diversos aspectos de sua obra é crescente. Entre 1980 e 1989, quarenta trabalhos publicados; entre 1990 e 1999, 145; entre 2000 e 2006, 162 trabalhos (Mariosa, 2007).

\section{Questões de método para o estudo da educação pública na obra de Florestan Fernandes}

Os estudos de Florestan sobre a educação aqui examinados são constituídos, na maior parte, por textos de intervenção pública do sociólogo (Fernandes, 1966, 1975, 1984, 1989a, 1995a) e por seus escritos políticos e parlamentares (Fernandes, 1989b, 1991b). Objetivando compreender as mudanças em suas análises sobre os entraves que impossibilitaram a real universalização da educação pública, gratuita, laica e unitária no Brasil, investiguei seus trabalhos teóricos sobre a formação social brasileira e suas classes. A partir de considerações teóricas e epistemológicas, elaborei critérios de seleção que me possibilitaram centrar a análise em Fernandes (1973, 1977, 1978, 1981 e 2008).

Na definição do que seriam suas obras de maior rigor teórico, a proposição mais contundente foi elaborada por Freitag (1987). A autora propugna que, no contexto de seu afastamento da Universidade pelo AI-5, existe uma ruptura epistemológica que separa suas obras científicas "acadêmico-reformistas" - inspiradas na sociedade democrática planejada de Mannheim -, como na Campanha em Defesa da Escola Pública, no início de 1960, de suas obras "político-revolucionárias", em que Marx é a referência central. Conforme Freitag, os textos do socialista romperam com o sociólogo, dando margem à compreensão de que, em seus textos maduros "político-revolucionários", Florestan deixou de fazer ciência. É como se o socialismo e a defesa da revolução socialista tivessem presidido os protocolos científicos da pesquisa, esvaziando o rigor de sua "sociologia marxista". Diante de críticas semelhantes às de Freitag, Florestan sustentava, alternativamente, que "os protocolos de pesquisa (...) são fornecidos pelos problemas investigados" (Fernandes, 1978, p. 127). Justo por se valer de autores provenientes de outras perspectivas teóricas, como Durkheim e Weber, Florestan foi criticado por seu ecletismo, ainda que este, na avaliação de Cohn (1987), fosse "bem temperado". Na terceira parte de $R B B$, como observa Coutinho (2000), a matriz teórica é inequivocamente marxista e os conceitos provenientes de outras tradições são trabalhados no interior de sua análise marxista, refinando as categorias explicativas, como no uso da noção weberiana de "possuidores de bens" e "não possuidores de bens", para dar conta de uma configuração de classes sociais que, no Brasil, é distinta da experiência clássica europeia. 
Entretanto, Freitag tem razão em ressaltar mudanças importantes na obra de Fernandes a partir de 1967. Nos termos de Cardoso (1996), em Sociedade de classes e subdesenvolvimento (Fernandes, 1981; publicado originalmente em 1968), uma nova problemática se consolida em sua obra: o capitalismo dependente. Diferente de Freitag, não a concebo como uma ruptura epistemológica, ${ }^{1}$ mas como um longo processo de elaboração pleno de retificações e novas sínteses em seus trabalhos. Decorre dessa compreensão que não trabalho com a proposição de que existem dois momentos distintos na elaboração de nosso autor sobre a educação: pré e pós-ruptura. A objeção à tese de Freitag é de dupla ordem: metodológica e teórica. Em artigo publicado quase vinte anos depois de ter apresentado sua tese em 1986 (Freitag, 2005), a autora precisa que:

\footnotetext{
Para comprovar a minha tese da ruptura, apoiei-me na coletânea de textos escritos na primeira fase do acadêmico reformador (Educação e sociedade no Brasil, 1966) e em textos da segunda fase, a do político revolucionário (Universidade brasileira: reforma ou revolução?, 1975) e textos como A questão da USP e USP: passado e presente, ambos de 1984. (p. 5)
}

Encontro dois problemas aqui: 1) os textos em que a autora identifica a ruptura não são sincrônicos. Embora Universidade brasileira: reforma ou revolução? tenha sido publicado em 1975, os seus capítulos foram elaborados em 1965 (1), 1968 (5), sendo posteriores apenas os capítulos 6 e 8 (1974). A questão da USP foi publicado em 1984. Assim, a autora poderia ter explicitado melhor sua periodização, afinal, o intervalo entre as produções consideradas pode chegar a quase vinte anos; 2) a principal objeção, em termos de método, é que as mudanças teóricas na obra florestaniana deveriam ser buscadas em textos que o próprio autor e seus interlocutores mais sistemáticos situam como "marcantes" em sua trajetória. No plano teórico, no período identificado por Freitag como de ruptura, as obras que o próprio autor considera mais relevantes (Fernandes, 1977) são Sociedade de classes e subdesenvolvimento (1968) e A revolução burguesa no Brasil (1975).

Florestan (1977) reconstitui o percurso teórico que o leva a concluir RBB e destaca que a obra está em conexão com A integração do negro na sociedade de classes (1964) e com Sociedade de classes e subdesenvolvimento (1968), esta última coetânea das duas primeiras partes de $R B B$. O longo tempo de maturação desta última obra, lembrando que a primeira parte foi elaborada em 1966 e a última parte (III) em 1974, indica que sua concepção não foi abrupta, fruto de uma demanda conjuntural episódica, resultante do amadurecimento de sua reflexão sobre a realidade empírica do capitalismo monopolista em uma violenta ditadura civil-militar.

O Estado autocrático (...) demonstrou que não existiam "alternativas possíveis" dentro do capitalismo dependente. Foi, de novo, através de uma combinação das atividades práticas com o trabalho acadêmico que percorri esse último circuito, pelo qual consegui 
eliminar o impacto da condição burguesa e do radicalismo democrático burguês sobre minha própria reflexão sociológica. (Fernandes, 1977, p. 202)

Longe de representar o abandono do esforço interpretativo, científico, sua obra magna coroa todo um longo percurso no qual Fernandes consolida um quadro teórico rigoroso, sutil, sobre a formação histórico-social brasileira, concebida por ele como um processo original, sui generis, distinto, em muitos sentidos, da linha evolutiva imaginada, seja pela dita teoria da modernização, como no esquema de W. W. Rostow (1964), seja pelo materialismo histórico referenciado nas proposições da Terceira Internacional, grosso modo, incorporadas na leitura do Partido Comunista Brasileiro (PCB).

O corolário dessa forma de interpretação da realidade brasileira é que as frações burguesas locais dominantes, por terem se associado às frações burguesas hegemônicas, no contexto do capitalismo monopolista, não podem empolgar projetos capazes de configurar uma revolução burguesa clássica, anti-imperialista, para assegurar um projeto de nação autopropelido. Ao se adequarem às relações de classes características do capitalismo dependente, os setores dominantes, conforme Fernandes (2008), naturalizaram o modus operandi da repressão, da cooptação e do constrangimento sobre os trabalhadores para que estes se conformem com elevados níveis de exploração do trabalho e com direitos sociais minimalistas.

Essa nova problemática tem importantes repercussões em sua análise da educação pública. Cotejando os dois momentos mais marcantes de sua elaboração sobre a educação - o da Campanha em Defesa da Escola Pública (1958-1966) e o de suas intervenções na Constituinte e na LDB dos anos de 1990 -, é possível sustentar que a conceituação da formação histórico-social brasileira como capitalista dependente modifica sua interpretação sobre a natureza dos obstáculos que levam os setores dominantes a não realizar a reforma educacional de natureza democrática e republicana: enquanto em Educação e sociedade no Brasil o sociólogo confere enorme importância ao problema da "demora cultural", nos embates pela constituinte e pela LDB, ele compreende que as reformas educacionais universais são obstaculizadas pelo capitalismo dependente e pela forma específica da Revolução Burguesa no Brasil.

\section{Capitalismo dependente e a Revolução Burguesa no Brasil}

Os problemas de fundo de RBB são: (i) a formação histórica do capitalismo no Brasil, (ii) os nexos entre as classes e frações de classe localizadas no país e as classes do núcleo hegemônico, e as particularidades advindas dessas relações na Revolução Burguesa no Brasil, e (iii) as vias e possibilidades para o desenvolvimento autônomo. Em RBB, Florestan faz uma análise sobre a formação social brasileira que é distinta de todos os "intérpretes" do país. 
Como Prado Jr. (1987), Florestan critica as concepções majoritárias do PCB que sustentavam a estratégia do VI Congresso da Terceira Internacional (1928). Nesta, o atraso econômico, político e social seria decorrente da permanência de formas pré-capitalistas e semifeudais. Assim, a estratégia socialista teria que envolver duas etapas distintas: inicialmente, compor com a chamada burguesia nacional de vocação anti-imperialista, objetivando realizar uma revolução democrático-burguesa. Na sequencia, lutar pelo socialismo (Gorender, 1987, p.250-251).

Prado Jr. e Florestan, distintamente, sustentam que, na virada para o século XX, o Brasil já era plenamente capitalista (Fernandes, 2008, p. 263). Contudo, conforme Coutinho (2000), os dois divergem sobre desde quando o país era capitalista. Para Prado Jr., em virtude da circulação de mercadorias na economia-mundo, o Brasil foi capitalista desde o período colonial; Florestan argumenta que a produção da base material do período colonial e, em grande parte, do período imperial não era propriamente capitalista, pois estava assentada em mecanismos extraeconômicos de submissão do trabalho ao capital. Para Florestan, o mercado capitalista moderno no Brasil foi forjado em três períodos: 1) fase de eclosão de um mercado capitalista especificamente moderno (transição neocolonial), compreendendo, grosso modo, a Abertura dos Portos (1808) até 1860; 2) fase de formação e expansão do capitalismo competitivo (1860-1950) e 3) fase de irrupção do capitalismo monopolista, a partir dos anos de 1950 e, sobretudo, a partir de 1964 (Fernandes, op. cit., cap. 6).

A análise florestaniana preconiza que o processo da Revolução Burguesa, que possibilitou o capitalismo competitivo e, depois, o monopolista, possui particularidades em relação às experiências "clássicas" europeias e dos Estados Unidos da América. Mais precisamente: trata-se de uma "revolução não clássica". O que é particular no Brasil não é a distinta temporalidade (seu caráter retardatário): não há repetição da história dos países do núcleo hegemônico nos países ditos subdesenvolvidos (idem, ibid., p. 340). O que é particular é a forma de articulação entre o desenvolvimento desigual interno e o imperialismo, situação conceituada como "capitalismo dependente". Existe aqui uma interessante proximidade de sua tese com a análise de Lênin sobre a via prussiana, como postula Coutinho (2000), similaridade que possivelmente foi amadurecida em seu período de estudos em Toronto, quando Florestan reexaminou a obra de Lênin.

A principal inovação teórica do período foi elaborada em Sociedade de classes e subdesenvolvimento: o conceito de capitalismo dependente (Cardoso, 1996). Nos termos de Florestan, o capitalismo dependente é:

Uma situação específica, que só pode ser caracterizada através de uma economia de mercado capitalista duplamente polarizada, destituída de autossuficiência e possuidora, no máximo, de uma autonomia limitada. Nos planos da estrutura, funcionamento e diferenciação do sistema econômico, a dupla polarização do mercado suscita uma 
realidade nova e inconfundível. Trata-se de uma economia de mercado capitalista constituída para operar, estrutural e dinamicamente: como uma entidade especializada, ao nível da integração do mercado capitalista mundial; como uma entidade subsidiária e dependente, ao nível das aplicações reprodutivas do excedente econômico das sociedades desenvolvidas; e como uma entidade tributária, ao nível do ciclo de apropriação capitalista internacional, no qual ela aparece como uma fonte de incrementação ou de multiplicação do excedente econômico das economias capitalistas hegemônicas. (Fernandes, 1968, p. 36-37)

A dissociação das temporalidades característica da "demora cultural" é reinterpretada à luz da proposição do desenvolvimento desigual do capitalismo. Nesta, diz Florestan, os tempos históricos desiguais coexistem e se interpenetram: o velho e o novo se complementam e se realimentam. A heteronomia é econômica, política, social, ideológica e moral. "A integração econômica satelizada se desdobra culturalmente, na construção das mentalidades e das aspirações, de tal modo a criar comportamentos, expectativas e laços que reforçam a condição heteronômica" (Cardoso, 1996, p. 109).

Florestan deixa de conceber a eficácia da dependência cultural como fator explicativo do bloqueio do desenvolvimento autônomo. O núcleo do problema está no capitalismo dependente que, entretanto, não exclui a questão cultural, mas a redefine no escopo das tensões entre desenvolvimento autônomo e capitalismo dependente.

É, pois, inapropriado falar em ruptura entre o socialista e o sociólogo: é o avanço na teoria (o capitalismo dependente e a forma específica da Revolução Burguesa) que o leva a redimensionar sua condição de socialista. Florestan rompe por completo com a compreensão de que as frações burguesas locais poderiam conduzir uma "revolução dentro da ordem", de natureza republicana e democrática, em que as políticas sociais universais poderiam avançar. Somente pela ação protagônica dos subalternos tais reformas poderiam ser encaminhadas de modo resoluto.

\section{Campanha em Defesa da Escola Pública}

Esta seção está dedicada à intervenção de Florestan na Campanha em Defesa da Escola Pública e coloca em relevo o embate político que convulsionou o final do processo de tramitação da Lei n. 4.024/1961 e, também, sua caracterização dos desafios educacionais. A principal base empírica da caracterização dos embates e dilemas da Campanha é o seu alentado livro Educação e sociedade no Brasil (1966), agregando, contudo, obras posteriores em que o sociólogo avalia o processo, como no Prefácio de $O$ desafio educacional (1989a).

Desde a juventude, Florestan esteve engajado de modo original na luta pela educação pública. Em 1945, militou em uma organização trotskista, o Partido Socialista Revolucionário (PSR), que propôs um programa objetivando a unificação de 
setores de esquerda após o Estado Novo, "Anteprojeto de programa técnico-eleitoral". No plano político, reivindica (i) o ensino leigo e a (ii) liberdade de cátedra e de pesquisa: "O pensamento não viciado por paixões, inclusive pela paixão do medo, é que fecunda tanto a ciência como a arte" (Coligação Democrática Radical..., 1945. In: Martinez, 1998, p. 233). No plano social, a agenda liberal-democrática "escola pública, gratuita, laica, universal" contém elementos socialistas, como "a proibição de trabalho aos menores de 14 anos, compreendendo que o trabalho precoce impede o direito à educação" (idem, ibid., p. 241) e a defesa de que as bolsas utilizadas na rede privada, custeadas pelo Estado, fossem convertidas em bolsas para que as crianças e jovens não necessitassem trabalhar. Na organização da educação, o Programa apregoa "um plano estratégico nacional", submetido a "direção colegiada" dos educadores.

A Campanha em Defesa da Escola Pública surgiu no contexto da etapa final da tramitação do projeto de LDB, quando entrou em cena o Substitutivo Lacerda no final de 1958, incorporando as recomendações do III Congresso Nacional dos Estabelecimentos Particulares de Ensino de 1948. Na leitura de Florestan, com o projeto de LDB Clemente Mariano, "os 'pioneiros da educação nova' queriam civilizar a sociedade civil” (Fernandes, 1991a, p. 32), “(...) acelerar os ritmos e encurtar o tempo das reformas educacionais inerentes à revolução burguesa", objetivando "a defesa da herança republicana e da filosofia democrática da educação" (Fernandes, 1963, p. 115).

As resistências a um projeto que, afinal, traduzia anseios liberais e burgueses impactam profundamente Florestan, que constata a falta de disposição de grande parte das frações burguesas em avançar uma reforma classicamente republicana: "Pouco a pouco os mentores das escolas particulares, sob a liderança e com o apoio influente do clero católico, interferiram na tramitação do projeto de lei, alterando por completo sua orientação e conteúdo" (idem, ibid.). Florestan chega a uma conclusão que, posteriormente, será teorizada sistematicamente em $R B B$ : nem mesmo reformas liberais são abraçadas pelos setores dominantes que, mais do que descaso, passam a se engajar, de modo organizado e orgânico, contra a modesta reforma educacional que poderia ser operacionalizada pela LDB. O sociólogo compreende que a sociedade civil reacionária estava organizada: “Os segmentos da sociedade civil que são capazes de agir organizadamente em defesa de seus interesses e valores sociais (...) são as camadas dominantes" (Fernandes, 1966, p. 362).

A Campanha possibilitou a Florestan refinar sua própria elaboração teórica sobre a educação: "A instrução vem a ser um privilégio econômico e social sob dois aspectos: da situação de classe das famílias e do grau de prosperidade de cada região da sociedade brasileira" (idem, 1963, p. 112). O descompasso entre a educação realmente existente e o papel construtivo da educação para superar os limites do "subdesenvolvimento" foi sintetizado em O dilema educacional brasileiro, texto elaborado em 1960: 
(...) Como ocorre em outros países subdesenvolvidos, ele é de fundo institucional. O sistema educacional brasileiro abrange instituições escolares que não se ajustam, nem qualitativa nem quantitativamente, a necessidades educacionais prementes, que são compartilhadas em escala nacional ou que variam de uma região para outra do país. Daí ser urgente e vital alterar a estrutura, o funcionamento e o modo de integração das instituições. (Fernandes, 1976, p.419)

A polarização entre a escola pública e a privada tem como divisor de águas o Estado que, em sua acepção, deveria gozar de autonomia para estruturar a educação pública:

Em questões de interesse coletivo, ensina-nos nossa experiência histórica, a lei tem sido um fator altamente construtivo. Onde o Estado se omite e não impõe normas consentâneas com o interesse da coletividade, o livre jogo dos comportamentos espontâneos revela-se, em regra, incapaz de promover os ajustamentos desejáveis. (Idem, 1966, p. 361)

A despeito de, em seus escritos pós-1967, sua compreensão sobre o caráter particularista do Estado ser mais bem trabalhada, por inserir o Estado na análise da correlação de forças entre as classes sociais, dificilmente sua concepção sobre o Estado nos embates da Campanha pode ser tida como ingênua e idealizada. Com efeito, em Florestan, a possibilidade de um Estado educador está subordinada à "democratização do poder e da riqueza", consignas estranhas à tradição liberal. Ademais, no que diz respeito à educação, "o que preocupa (...) é [como] disciplinar [o Estado] de modo a impedir (...) a concentração e o monopólio de poder nas mãos de pequenos grupos" (idem, ibid., p. 370).

Congruente com sua análise de que é preciso democratizar o poder e a riqueza, Florestan buscou alargar o movimento para além dos liberais renovadores, liderados por Anísio Teixeira e Fernando Azevedo, pelo grupo em torno de O Estado de S. Paulo (OESP), liderado por Roque Spencer Maciel de Barros e Laerte Ramos de Carvalho, e pelo próprio círculo da Cadeira de Sociologia I por ele dirigida e que contava, entre outros, com a presença de Octavio Ianni e Fernando Henrique Cardoso. Florestan incorporou os sindicatos na luta em defesa da escola pública, contribuindo para a realização da I Convenção Operária em Defesa da Escola Pública (1961). Essa experiência corrobora que a sua defesa da agenda liberal-democrática ao longo da Campanha não traduz inteiramente sua própria concepção de educação, pois, a despeito de sua inequívoca liderança, como sublinha Saviani (1996), a hegemonia é liberal.

Ao avaliar a aprovação da Lei n. 4.024/1961, Florestan argumentou que seu sentido geral negativo ao ensino público foi preservado: "no essencial, o projeto ou ficou como estava ou ficou pior" (1966, p. 514). Como que antecipando o que estava por vir, compreendeu a gravidade das conquistas dos privatistas: "conservaram o Conselho Federal de Educação como um autêntico 'cavalo de Tróia' dos interesses privatistas no seio do Poder Executivo e não trepidaram diante da dilapidação do 
erário público para servir aos interesses ilegítimos dos estabelecimentos particulares de ensino (...)" (Fernandes, 1966, p. 508-512). Ademais, avalia que a nova LDB se omite diante dos "problemas do desenvolvimento", mantendo a educação em uma lógica conservantista (idem, ibid., p. 527), deixando de operar "como 'fator social construtivo' nas relações do sistema educacional com o meio social circundante" (p. 529).

Florestan constata os limites reformistas do arco nacional-desenvolvimentista representado por Jango e, em tom de tristeza, da própria Campanha. Ao final, o governo de Jango sancionou o projeto após mudanças consideradas pelo sociólogo como superficiais. Em entrevista ao OESP, em 1962, Florestan afirmou que a LDB sancionada foi objeto de "congraçamento entre educadores reformistas e as correntes privatistas no poder" (Fernandes, 1966, p. 526). Em síntese, Florestan atribuiu a indisposição reformista dos setores dominantes à demora cultural: "o dilema número um da sociedade brasileira hodierna é a demora cultural (...): existe uma resistência residual intensa à mudança, a qual se torna sociopática nos círculos conservantistas do país (...)" (idem, 1963, p. 138).

Essa avaliação, após Sociedade de classes e subdesenvolvimento (1968), será redefinida com a nova problemática do capitalismo dependente, alterando sua interpretação sobre os dilemas da educação no período que compreende os embates da constituinte até seu falecimento, em 1995, quando o sociólogo estava nas trincheiras das lutas pela nova LDB.

\section{Educação: período da Constituinte}

Embasado por seus estudos sobre o capitalismo dependente e a heteronomia cultural, Florestan dedicou diversos trabalhos à problemática da reforma educacional nos anos de 1980 e 1990. Em O desafio educacional (1989a), ele nos oferece uma boa síntese de seu pensamento educacional nos anos de 1980: "um vulcão que parecia extinto". No Prefácio, aponta o que lhe parece a prioridade fundamental: "colocar os trabalhadores, os excluídos e os oprimidos (...) nas malhas da rede escolar" (Fernandes, 1989a, p. 9). Reconhece, por conseguinte, que "o principal desafio socialista na esfera educacional ainda é calibrado 'pelas reformas burguesas da educação'" (idem, ibid., p. 9).

Para tanto, Florestan defende que, no processo da Constituinte, a despeito de seus limites, os subalternos não poderiam abrir mão da disputa pelos direitos sociais nos marcos da ordem:

Não se deve alimentar a ilusão de que as normas legais "resolvem", por si mesmas, os dilemas sociais. Mas os Pioneiros estavam certos: elas criam deveres mínimos (do poder público [...]), estimulam a distribuição crescente das oportunidades educacionais 
e abrem aos trabalhadores canais de acesso a todos os níveis de ensino. (Fernandes, 1995a, p. 26)

Em “O novo ponto de partida", conferência de abertura da II Conferência Brasileira de Educação (1982), Fernandes (1989a) avalia positivamente o papel construtivo dos trabalhadores na conjuntura. O ciclo de greves no ABC Paulista e a rápida reorganização das entidades dos trabalhadores corroboram sua análise. Diante dessa situação, ele considera que poderia ser possível um maior protagonismo dos trabalhadores na sociedade civil, podendo acabar com a "apatia social" e "fazendo-nos aproximar (...) de uma experiência autenticamente republicana e democrática" (p. 13-19).

Frente ao ascenso das lutas sociais dos anos de 1980, a tarefa dos educadores, em sua concepção, não poderia ser a mesma da Campanha e das reformas de base do início dos anos de 1960. "Esse passado não está morto", mas "não se trata mais de colocar o cidadão no eixo da reflexão pedagógica transformadora". É crucial que o educador possa reeducar-se como classe trabalhadora. Pensar a educação sob a ótica das necessidades culturais da classe trabalhadora, prossegue Fernandes, requer uma "pedagogia fundada no trabalho como valor central" (Fernandes, 1989a, p. 17).

Na perspectiva de seu mandato parlamentar, as prioridades da Carta, em matéria de educação, foram sintetizadas em três conjuntos: 1) assegurar a todos igualdade efetiva das oportunidades educacionais como norma imperativa e autoaplicável, o que teria que abranger igualdade (supressão da desigualdade) na sociedade civil, garantindo a educação pública, gratuita e laica como dever do Estado em todos os níveis; 2) conferir à escola a condição de principal "laboratório" da sociedade civil civilizadora, pluralista e democrática, o que envolve a valorização dos trabalhadores da educação, buscando reverter a situação de degradação deliberada; 3 ) a autoemancipação pedagógica em escala nacional, no escopo do desenvolvimento autônomo, em oposição à lógica dos "pacotes educacionais" de que somos vítimas voluntárias (Fernandes, 1989a, p. 134-135).

Florestan apresentou 94 emendas, ${ }^{2} 46$ relacionadas à educação, das quais 27 são de natureza conceitual ou sobre a organização da educação brasileira, sete de questões relativas à Ciência e Tecnologia $(C \& T)$ e três sobre a universidade. Entre suas emendas mais relevantes, encontramos: a) direito dos povos indígenas à educação bilíngue; b) autonomia universitária (art. 207); c) diversos dispositivos de apoio às atividades de C\&T; d) gratuidade da educação para crianças de 0 a 6 anos em instituições especializadas; e) obrigatoriedade da educação pública e gratuita dos 6 aos 16 anos; f) proibição de ensino religioso nas escolas públicas; g) verbas públicas exclusivamente para as escolas públicas; h) financiamento: a União aplicará anualmente não menos de $18 \%$, e os estados, o Distrito Federal e os municípios não menos 
de $25 \%$ das suas receitas totais (e não apenas a resultante de impostos) na manutenção e desenvolvimento das atividades de ensino; i) dispositivo que preveja, em dez anos, que nenhuma instituição privada receberia verbas públicas e, j) enfrentando a questão do caráter público da educação estatal, criação do Conselho Nacional de Desenvolvimento da Educação, o qual deverá possuir autonomia administrativa e financeira frente ao MEC, bem como autoridade para estabelecer programas e políticas a serem realizados através do Plano Nacional de Educação. Esta Emenda, embora aprovada, não consta do texto final.

$\mathrm{Na}$ avaliação de Florestan, "A Constituição que esta sendo elaborada realizava vários avanços, mas não é aquela que responde às exigências da situação histórica". "É uma Constituição heteróclita". O peso do poder da Igreja católica, em sua feição mais reacionária e obscurantista, e da bancada privatista, abrigada no "centrão", um agregado de parlamentares a serviço de quem realmente comandou a Constituinte - "capital estrangeiro, capital nacional, Estado plutocrático" -, impôs retrocessos importantes nos dispositivos educacionais da Carta, como a admissão de verbas públicas para as instituições privadas (art. 213), possibilitando o ensino religioso nas escolas públicas (art. 210), “o ensino é livre à iniciativa privada" (art. 209), etc. (Fernandes, 1989b, p. 121).

\section{Um novo ponto de partida na luta pela LDB}

Após o áspero período da Constituinte, a conjuntura tornou-se ainda mais adversa - Governo Collor de Mello, Queda do Muro de Berlim, avanço da ideologia neoliberal e descenso das lutas sociais. O principal embate pela educação pública, no terreno parlamentar, dar-se-ia na elaboração da nova LDB: “Inquietos, os setores privatistas montam, de novo, um funesto campo de batalha para manter suas vantagens relativas. É nosso dever enfrentá-los, sem desalento, para derrotar sua hegemonia e mercantilismo" (Folha de S. Paulo, 19 ago. 1991, apud Fernandes, 1995, p. 26).

Por parte dos educadores, "formou-se, desde o processo constituinte, o Fórum Nacional em Defesa da Escola Pública, (...) a primeira (e, pela organicidade, a única) tentativa de participação popular no processo legislativo" (Fernandes, op. cit., p. 48). Destaca como importante que, distintamente da LDB de 1961, o primeiro projeto de LDB protocolado pelo deputado Octavio Elísio (PSDB/MG) na Câmara, em dezembro de 1988, tem origem na elaboração da sociedade civil, incorporando as contribuições da XI Reunião da ANPEd (abril de 1988) e os aperfeiçoamentos da mesma na V CBE (agosto de 1988).

Sobre o projeto do deputado Elísio, Florestan considera que sua proposta mais ousada e modernizadora é "a inserção do trabalho produtivo em todos os níveis da 
educação escolar". “É vital associar educação escolar e trabalho produtivo", mas "não como um reforço do aprisionamento do trabalho pelas conveniências do capital: mas como fator de socialização crítica libertária, igualitária e democrática do ser humano" (Fernandes, 1989a, p. 28). Para que o trabalho possa ser um princípio educativo, duas dimensões são imperativas: 1) "Varrer do corpo e da cabeça do jovem a aprendizagem que o socialize para ser um cidadão de segunda ou terceira categoria (...)" e 2) "fazer da integração à escola o centro de uma liberação crítica e total, que incentive a descoberta do eu e do nós coletivo do futuro trabalhador, como pessoa e como integrante de sua classe social" (idem, ibid., p. 263).

A concepção de que o futuro da nova LDB dependeria das lutas dos trabalhadores e, em especial, dos trabalhadores da educação marca uma importante diferença em relação à LDB anterior. Diante dos sinais de que os privatistas estavam promovendo uma ofensiva contra a LDB, Florestan sugere que as entidades deveriam modificar suas estratégias de ação (Fernandes, 1995, p. 55): “Telegramas (...), manifestos ingênuos e estereotipados e visitas de catequização aos gabinetes dos parlamentares (...) patenteiam os meios de ação política dos fracos" (idem, ibid., p. 58). Acima de tudo, prossegue o autor, "é preciso pressionar os parlamentares em suas bases, realizar conferências, pressão nas galerias e manifestações de massa". Em 21 de junho de 1991, o Fórum realizou uma manifestação em Brasília, reunindo cerca de 10 mil pessoas. Em sua apreciação, foram essas as atividades que mais impactaram os parlamentares vacilantes (ibid.).

Florestan estava ciente de que a correlação de forças exigia uma "conciliação aberta", mas, como é possível evidenciar na versão final da lei, as reformas contidas no projeto da Câmara não foram possíveis. Florestan vinha defendendo que os partidos de esquerda e os sindicatos tivessem outro tipo de engajamento na autoformação da classe para que as lutas pela educação pública fossem mais amplas. Contudo, reconhecia que a estratégia prevalecente na esquerda não privilegiava a educação pública popular como um eixo da luta social.

Em seus textos voltados diretamente para a questão do partido, Florestan considera imprescindível que os educadores se assumam como "classe para si" e forjem um projeto autônomo "da classe" em uma perspectiva unitária e universal para a educação pública. Em seus últimos escritos, tal alternativa passa pelo fortalecimento do locus escolar, espaço em que a autopedagogia da classe trabalhadora poderia ser levada adiante.

Muitas das tendências apontadas nos estudos de Florestan sobre as consequências da afirmação do capitalismo monopolista se confirmaram. As frações burguesas locais, por sua forma específica de associação com o imperialismo, não podem ser protagonistas de reformas sociais universalistas, sequer nos marcos da "revolução 
dentro da ordem", como os desfechos da LDB de 1961 e 1996 atestaram. O engajamento orgânico dessas frações na ditadura civil-militar e na contrarrevolução neoliberal corrobora a análise florestaniana sobre a Revolução Burguesa no Brasil. Se as frações burguesas não podem liderar a reforma educacional, o futuro da educação pública está nas mãos dos que vivem do próprio trabalho e são explorados. Entretanto, Florestan se preocupava com o fato de que as principais iniciativas de organização dos trabalhadores, a despeito da retórica socialista, pouco se importavam em "dar primazia à educação para e pelo socialismo" (Fernandes, 1991b, p. 73).

Tomando como referência a periodização de Florestan, já se passaram 50 anos desde a consolidação do capitalismo monopolista no país, agora sob hegemonia de sua fração financeira e, particularmente, rentista. Neste intervalo de tempo aconteceram profundas alterações nas forças sociais que atuam na educação, muitas delas previstas por Florestan. Os setores privatistas se fortaleceram profundamente, quando comparados com as suas ações na LDB de 1961. Está em curso uma internacionalização de novo tipo no setor, por meio de fundos de investimentos multinacionais (private equity), em geral com ações nas bolsas de valores, que vêm promovendo vertiginosa concentração da educação superior privada. $O$ financiamento do poder público, seja por meio de isenções tributárias, como no Programa Universidade para Todos, seja por meio de juros subsidiados, como no Fundo de Financiamento Estudantil, alcança, atualmente, as instituições estritamente mercantis que não necessitam se ocultar sob o manto da filantropia.

Desde 1945, Florestan defendia a laicidade da educação pública como parte da pauta política dos trabalhadores. Hodiernamente, a questão religiosa desborda a ação da Igreja Católica que logrou firmar uma concordata com o governo brasileiro, em novembro de 2008 (Cunha, 2009). A expansão do pentecostalismo é indissociável da ramificação dessas igrejas no Parlamento e no Executivo, alterando a relação público-privado. Diversas redes municipais e estaduais vêm contratando representantes das seitas para ocuparem a docência na escola pública em nome do "multiculturalismo".

Florestan propugnou que segue sendo necessário ter como horizonte o direito de todos os que possuem um rosto humano à educação, capaz de fomentar a "imaginação inventiva" como dever do Estado, por meio da universalização da escola pública, gratuita, laica, em todos os níveis. Entretanto, de modo mais dramático do que no início dos anos de 1960, como chamar de pública uma educação que, embora ofertada nas instituições estatais, é inteiramente perpassada de particularismos? Florestan insiste "no fortalecimento da autonomia relativa da escola" e na defesa de que esta autonomia tem que estar "relacionada dialeticamente com a independência econômica, com a emancipação nacional e com a revolução democrática" (Fernandes, 1989a, p. 131). Os professores precisam ser sujeitos da autoconstrução da escola 
pública e, para isso, a autoformação como classe é imprescindível, pois a questão educacional não se resolve no âmbito econômico-corporativo: é parte do momento ético-político, pois está inscrita na estratégia política do socialismo (Fernandes, 1991b). A obra florestaniana permite concluir que a enorme batalha das ideias em torno do sentido do público no século XXI é radicalmente estratégica, especialmente quando, no Estado existente, o privado possui enorme supremacia. O diálogo não dogmático sobre sua obra oferece aportes que podem enriquecer a "imaginação inventiva" dos educadores e, desse modo, promover melhores condições para erigir um novo ponto de partida para as lutas pela escola pública.

\section{Notas}

1. Nos termos de Bachelard (2004), a ruptura constitui não apenas uma nova problemática, expressão do corte epistemológico, mas a instauração de um novo domínio da ciência (como na física newtoniana e na física quântica).

2. As emendas aqui examinadas têm como fonte o trabalho de Neves (2009).

\section{Referências}

BACHELARD, G. Ensaio sobre o conhecimento aproximado. Rio de Janeiro: Contraponto, 2004.

CANDIDO, A. Amizade com Florestan. In: D'INCAO, M.A. (Org.). O saber militante. São Paulo: Unesp; Rio de Janeiro: Paz \& Terra, 1987. p. 34.

CARDOSO, M.L. Florestan: a criação de uma problemática. Estudos Avançados, São Paulo, v. 10, n. 26, p. 89-128, 1996.

COHN, G. O ecletismo bem temperado. In: D'INCAO, M.A. (Org.). O saber militante. São Paulo: Unesp; Rio de Janeiro: Paz \& Terra, 1987. p. 48-53.

COLIGAÇÃO DEMOCRÁTICA RADICAL: anteprojeto de programa técnico-eleitoral, 1945. In: MARTINEZ, P.H. (Org.). Florestan ou o sentido das coisas. São Paulo: Boitempo, 1998. p. 233.

COUTINHO, C.N. Cultura e sociedade no Brasil. Rio de Janeiro: DP\&A, 2000.

CUNHA, L.A. A educação na Concordata Brasil-Vaticano. Educação E Sociedade, Campinas, v. 30, n. 106, p. 263-280, jan./abr. 2009.

FERNANDES, F. Sociologia numa era de revolução social. São Paulo: Nacional, 1963.

FERNANDES, F. Educação e sociedade no Brasil. São Paulo: Dominus; Edusp, 1966. 
FERNANDES, F. Capitalismo dependente e classes sociais na América Latina. Rio de Janeiro: Zahar, 1973.

FERNANDES, F. A universidade brasileira: reforma ou revolução? São Paulo: AlfaÔmega, 1975.

FERNANDES, F. O dilema educacional brasileiro. In: PEREIRA, L.; FORACCHI, M.M. Educação e sociedade. São Paulo: Nacional, 1976.

FERNANDES, F. A sociologia no Brasil. Petrópolis: Vozes, 1977.

FERNANDES, F. A condição de sociólogo. São Paulo: Hucitec, 1978.

FERNANDES, F. Sociedade de classes e subdesenvolvimento. 4. ed. Rio de Janeiro: Zahar, 1981.

FERNANDES, F. A questão da USP. São Paulo: Brasiliense, 1984.

FERNANDES, F. O desafio educacional. São Paulo: Cortez, 1989a.

FERNANDES, F. A Constituição inacabada, vias históricas e significado. São Paulo: Estação Liberdade, $1989 b$.

FERNANDES, F. Depoimento. In: MEMÓRIA viva da educação brasileira. Brasília, DF: Inep, 1991a. v. 1.

FERNANDES, F. O PT em movimento: contribuição ao I Congresso do Partido dos Trabalhadores. São Paulo: Cortez; Campinas: Autores Associados, 1991b.

FERNANDES, F. Tensões na educação. Salvador: Sarah Letras, 1995a.

FERNANDES, F. Reflexão sobre o socialismo e a autoemancipação dos trabalhadores. São Bernardo do Campo: Sindicato dos Metalúrgicos de São Bernardo e Diadema, 1995b.

FERNANDES, F. A Revolução Burguesa no Brasil. 5. ed. São Paulo: Globo, 2008.

FREITAG, B. Democratização, universidade, revolução. In: D’INCAO, M.A. (Org.). O saber militante: ensaios sobre Florestan Fernandes. São Paulo: Unesp; Rio de Janeiro: Paz \& Terra, 1987.

FREITAG, B. Florestan Fernandes: revisitado. Estudos Avançados, São Paulo, v. 19, n. 55, set./dez. 2005. Disponível em: <http://www.scielo.br/scielo.php?script=sci_ arttext\&pid=S0103-40142005000300016\&lng=pt\&nrm=iso $>$.

FREITAS, C.C.; LEHER, R.; PINHEIRO, D. Estado da arte da presença de Florestan Fernandes na produção acadêmica brasileira: análise de temas, categorias e obras citadas nas teses de doutorado 2000-2010. Brasília, DF: Ipea; Capes, 2011. (Relatório de pesquisa; versão preliminar). 
GORENDER, J. A Revolução Burguesa e os comunistas. In: D'INCAO, M.A. (Org.). O saber militante. São Paulo: Unesp; Rio de Janeiro: Paz \& Terra, 1987.

MARIOSA, D.F. Florestan Fernandes e a sociologia como crítica dos processos sociais. 2007. Tese (Doutorado) - Instituto de Filosofia e Ciências Humanas, Universidade Estadual de Campinas, Campinas.

NEVES, M.A. Florestan Fernandes: sociologia e política pela autonomia da nação. 2009. 132p. Dissertação (mestrado em Ciência Política) - Instituto de Pesquisas Universitárias do Rio de Janeiro, Rio de Janeiro. Publicado na Biblioteca Digital da Câmara dos Deputados. Disponível em: <http://bd.camara.gov.br/bd/bitstream/ handle/bdcamara/3609/florestan_fernandes_neves.pdf?sequence=1>. Acesso em: 10 maio 2011.

PRADO JUNIOR, C. A revolução brasileira. São Paulo: Brasiliense, 1987.

ROSTOW, W.W. As etapas do desenvolvimento econômico. Rio de Janeiro: Zahar, 1964.

SAVIANI, D. Florestan e a educação. Estudos Avançados, São Paulo, v. 10, n. 26, p. 71-87, 1996.

Recebido em 22 de março de 2012.

Aprovado em 14 de agosto de 2012. 